\title{
A Cenografia na UTFPR e a Participação na Quadrienal de Praga de 2019
}

\author{
Ismael Scheffler \\ Universidade Tecnológica Federal do Paraná - UTFPR, Curitiba/PR, Brasil \\ E-mail: ismaelcuritiba2@gmail.com
}

\section{Resumo}

O presente texto apresenta uma contextualização do ensino da cenografia na Universidade Tecnológica Federal do Paraná. São mencionados projetos de extensão, atividades curriculares de ensino no curso de Bacharelado em Design, eventos científicos e destinada atenção ao Curso de Especialização em Cenografia, demonstrando inter-relações entre as diferentes frentes. A seguir, são apresentadas informações sobre a produção do vídeo Laboratório de Experimentação do Espaço elaborado pela UTFPR para participar na Mostra dos Estudantes de Design da Performance e do Espaço na 14 ${ }^{\text {a }}$ Quadrienal de Praga, na República Tcheca, em 2019. Por fim, são feitas algumas reflexões sobre a atividade de culminância apresentada no documentário, a improvisação cenográfica em escala natural. O texto se caracteriza como um relato de experiências indicando algumas fontes teóricas do fundamento pedagógico.

\section{Palavras-chave}

Cenografia. Ensino. Extensão Universitária.

Quadrienal de Praga. Universidade Tecnológica

Federal do Paraná.
This paper presents a contextualization of the teaching of scenography at the Federal University of Technology - Paraná (UTFPR). We talk about extension projects, curricular teaching activities in the Bachelor of Design course, scientific events and we also mention the Specialization Course in Scenography, showing the interrelations between the different units. After, we present information about the video production Space Experimentation Laboratory created by UTFPR to participate in the Student Exhibition in the 14th Prague Quadrennial of Performance Design and Space, in the Czech Republic, in 2019. Finally, we reflect on the activity of culmination that is presented in the documentary, the scenographic improvisation on a natural scale. The text is an account of experiences indicating some theoretical sources from the pedagogical basis.

\footnotetext{
Scenography. Teaching. University Extension Courses. Prague Quadrennial. Federal University of Technology Paraná.
} 


\section{Introdução}

O ensino no campo da cenografia, entendido em sentido amplo, ainda carece de frentes de formação no Brasil. As próprias dificuldades em estabelecer-se uma terminologia única evidencia a diversidade de compreensões e práticas: cenografia, design cênico, desenho da cena, design da performance, elementos visuais e sonoros da cena, artes visuais cênicas, direção de arte são alguns termos empregados que interagem com meios e finalidades distintos.

Há uma herança cultural e diversos condicionantes no meio artístico e acadêmico que têm sido cada vez mais questionados pela própria prática da sociedade. A divisão em disciplinas, tanto dos conhecimentos, quanto das artes e dos signos teatrais conduziu a processos que hoje têm sido ainda mais problematizados. Isto, não apenas na produção teatral, mas também entre as diversas artes e entre a separação entre a arte e o consumo.

No caso do ensino de cenografia no âmbito da Universidade Tecnológica Federal do Paraná (UTFPR), alguns destes fatores se tonificam, afinal, se trata de uma universidade que não oferece cursos de graduação na área de Artes. A instituição oferece há várias décadas cursos diversos em design, como Decoração, Mobiliário (já extintos), ou os atuais Tecnologia em Design Gráfico e Bacharelado em Design (de formação generalista), além de graduação em Arquitetura e Urbanismo, Licenciaturas em Letras, Bacharelado em Comunicação Institucional, entre outros, predominando cursos de engenharias.

O teatro está presente regularmente na UTFPR desde 1972 (quando a instituição era ainda Escola Técnica Federal), por meio do grupo de teatro desenvolvido como atividade extraclasse para alunos secundaristas do ensino técnico, à época, atualmente como projeto institucional de extensão. O TUT (Teatro da Universidade Tecnológica) teve diversos professores-diretores desde então, com produções regulares de espetáculos (SCHEFFLER, 2008).

O presente texto apresenta alguns aspectos do ensino da cenografia na UTFPR perpassando em- preendimentos realizados entre 2009 e 2019. São mencionados projetos de extensão, como o Projeto de Extensão Desenvolvimento da Cenografia, atividades curriculares de ensino realizadas junto ao Bacharelado em Design, alguns eventos científicos e o Curso de Especialização em Cenografia, demonstrando-se inter-relações entre as diferentes frentes.

Estas informações contribuem para a compreensão da participação da UTFPR na Mostra dos Estudantes brasileiros na 14 ${ }^{\mathrm{a}}$ Quadrienal de Praga de Desenho e Espaço da Performance, em 2019, cujo trabalho foi o audiovisual Laboratório de Experimentação do Espaço, que apresenta aspectos pedagógicos a respeito desta disciplina ministrada pelo professor Ismael Scheffler no Curso de Especialização em Cenografia da UTFPR.

A Mostra das Escolas, mais recentemente chamada de Mostra dos Estudantes, é uma das seções competitivas da Quadrienal de Praga destinada à apresentação de trabalhos desenvolvidos na formação em cada país. Na realidade brasileira, são poucas as $\square$ escolas de cenografia $\square$ realmente existentes, tanto em cursos livres quanto em ensino superior. $\mathrm{O}$ ensino nas áreas visuais cênicas ainda se dá significativamente por meio de oficinas livres de curta e média duração, ou realizado de forma periférica em algumas universidades, principalmente em graduações de teatro, em disciplinas (algumas vezes mais isoladas) e em projetos de extensão.

No desenvolvimento deste artigo, duas participações curitibanas anteriores em Mostras das Escolas de cenografia são pontuadas, nas Quadrienais de Praga de 2003 e 2007, encabeçadas por Fernando Marés e Simone Pontes, respectivamente.

Em um segundo momento, são apresentadas informações sobre o contexto de produção do vídeo elaborado pela UTFPR para participar na seletiva nacional IMAGINA[trans] forma[inter]ação para a $14^{\mathrm{a}}$ Quadrienal de Praga. O vídeo foi um dos 25 projetos selecionados que compuseram a Mostra Brasileira dos Estudan- 
tes na PQ'19 e está disponibilizado no YouTube ${ }^{1}$. Por fim, são feitas algumas reflexões sobre a atividade de culminância apresentada no documentário referida como improvisação cenográfica em escala natural (1: 1).

\section{Contextualização}

Primeiras participações curitibanas na Mostra das Escolas

Curitiba esteve representada em Praga, em mostras estudantis, primeiramente nas edições de 2003 e 2007. Em 2003, uma mostra de trabalhos realizados sob a orientação do cenógrafo Fernando Marés integrou a Seção Mostra das Escolas de cenografia da Quadrienal de Praga. Os trabalhos expostos foram produzidos em uma oficina que ele dirigiu no Ateliê de Criação Teatral $(A C T)^{2}$. A participação se deu a partir do convite de J. C Serroni para que o ACT integrasse a mostra junto com outras duas instituições: Escola Livre de Teatro de Santo André / Núcleo de Cenografia e Indumentária (SP) e Espaço Cenográfico (SP) (ROCHA, 2016).

OACT havia sido criado em 2001 por Nena Inoue, Luis Melo e Fernando Marés para o desenvolvimento de pesquisas em teatro nos moldes do que Melo havia experimentado no Centro de Pesquisa Teatral, de Antunes Filho, em São Paulo. O empreendimento no ensino de cenografia não teve continuidade pois Marés, pouco tempo depois, mudou-se para Florianópolis (SC), embora tenha continuado a desenvolver trabalhos como cenógrafo na capital paranaense.

Na Quadrienal de Praga de 2007, foram expostos dois trabalhos estudantis realizados no contexto da Universidade Federal do Paraná (UFPR), dentre os 20 levados à Praga. Os projetos foram desenvolvidos em um Curso de Extensão de Cenografia vinculado ao Curso Técnico em Artes Cênicas/

1 Para assistir ao vídeo Laboratório de Experimentação do Espaço, acesse: https://www.youtube.com/watch?v=uGOZ_x3awWo. Acesso em: 09 jul. 2020.

2 No catálogo não constam os nomes dos alunos participantes pelo ACT (ROCHA, 2016).
Ator, realizado entre outubro e dezembro de 2006, dirigido pela professora Simone Pontes (NOVO, 2006). A coordenadora geral nacional da Mostra das Escolas foi feita por Lídia Kosovski, professora da UNIRIO e cenógrafa, tendo como proposta a obra dramatúrgica de Nelson Rodrigues. Foram 47 projetos inscritos dos quais 20 foram selecionados, abarcando de sete escolas (UNIRIO, UFRJ, UNICAMP, USP, Espaço Cenográfico, UFPA e UFPR (ROCHA, 2016)). De Curitiba, foram selecionados: Valsa n.6, desenvolvido por Gabrielle Windmuller de Siqueira, Thaciana B. D $\square$ Albuquerque e Sílvia Ricetti de Oliveira, e Beijo no asfalto, por Elis de Oliveira Ribeirete e Soraya Sugayama (KOSOVSKI; MARÉS, 2007). Pontes era arquiteta e cenógrafa, tendo formação com J. C. Serroni, em São Paulo, e Especialização em Teatro pela Faculdade de Artes do Paraná (FAP). Era professora efetiva e coordenadora do Curso Técnico. Suas iniciativas pedagógicas na área da cenografia, tanto em oficinas dadas pela Fundação Cultural de Curitiba quanto na UFPR, foram interrompidas precocemente com seu falecimento no mesmo ano de 2007 , aos 44 anos.

\section{Panorama do ensino de cenografia na UT-} FPR: de 2009 a 2019

Em 2005, Ismael Scheffler foi selecionado como docente em concurso público para se dedicar, a princípio, exclusivamente para o projeto do TUT, grupo de teatro institucional ${ }^{3}$ da Universidade Tecnológica Federal do Paraná (UTFPR), criado e mantido desde 1972, integrante do setor de $\square$ atividades comunitárias $\square$ (extensão). O ano coincidiu com a transformação da instituição em universidade, deixando de ser Centro Federal de Educação Tecnológica (CEFET). Isto ocasionou duplo impulso para o teatro: a efetividade docente (nos anos anteriores a função havia sido desempenhada por professoras substitutas) e uma revisão do entendimento do teatro na instituição e em suas práticas estudantis agora universitárias.

3 Ver página na internet: http://www.utfpr.edu.br/extensao/ cultura/teatro/curitiba. Acesso em: 09 jul. 2020. 
No afã de contribuir de maneira mais ampla com a formação teatral em Curitiba a partir da UTFPR, motivado pelas discussões geradas nos encontros das Manhãs Iluminadas, promovido pela ABrIC (Associação Brasileira de Iluminação Cênica), em Curitiba, durante os Festivais de Teatro de Curitiba, entre 2004 e 2010, também pela criação do curso de Bacharelado em Arquitetura e Urbanismo na UTFPR e da existência de graduações em design, e inspirado nas iniciativas que a cenógrafa e professora Simone Pontes havia iniciado na UFPR, Scheffler propôs a abertura do Curso de Especialização em Cenografia junto ao Departamento Acadêmico de Desenho Industrial (DADIN).

A primeira turma teve início em abril de 2009 e conclusão das atividades em julho de $2010^{4}$. Em 2013, foram iniciadas as aulas da segunda turma de Especialização em Cenografia. Os cursos de especialização não são contínuos, isto é, cada edição é uma em si, sendo que a abertura de uma nova turma corresponde a um novo projeto. Isto possibilita que cada curso tenha uma grade específica. Na UTFPR, isto implicou em variações de disciplinas ofertadas e carga horária em cada turma. Para esta segunda, ampliou-se a carga horária de $360 \mathrm{~h}$ para $470 \mathrm{~h}^{5}$.

A terceira turma da Especialização em Cenografia iniciou suas atividades em março de 2015 , e foi criado um novo curso iniciado neste mesmo momento: a Especialização em Artes Híbridas, idealizado em parceria com a professora Simone Landal. No segundo semestre, outro curso novo foi ofertado, a Especialização em Narrativas Visuais. De 2013 a 2019, a totalidade de cursos de especialização oferecidos pelo DADIN correspondeu a estes três, tendo, até 2019, quatro turmas de

4 Ver o capítulo a respeito em: SCHEFFLER, 2014. Foram formados 18 alunos no I Curso de Especialização em Cenografia. Para conhecer os trabalhos de conclusão de curso, ver: SCHEFFLER; LANDAL, 2016.

5 O II Curso de Especialização em Cenografia formou 15 alunos.
Cenografia $^{6}$, três turmas de Artes Híbridas e três de Narrativas Visuais (estando o teatro presente em todos) ${ }^{7}$.

No ano de 2013, Scheffler se propôs a assumir a disciplina optativa semestral Espaço cenográfico (60h) que, embora já constasse no projeto do curso de Bacharelado em Design, não era ofertada em razão não haver no Departamento Acadêmico de Desenho Industrial (DADIN) professor para o tema. Como disciplina optativa, é oferecida, desde então, em média uma vez ao ano.

A ementa, bastante ampla, considera múltiplos contextos estando próxima da ideia de cenografia aplicada quando a "linguagem cenográfica [é utilizada] para outros fins que não a expressão artística, dirigida ao contexto mais comercial das áreas da comunicação" (COHEN, 2007, p. 28). Compõe a ementa: História da cenografia. Identificação do espaço cenográfico. Vitrinas. Instalações. Exposições, estandes, feiras, lojas, museus. Espaço lúdico, espaço público para ver, estar e encenar. Parques temáticos. Igrejas, púlpitos, iluminação dramática. Materiais para montagens. Uso e pós-uso. Transporte, equipe. Não obstante, o teatro, como berço da cenografia e âmbito de seu desenvolvimento, assume espaço importante como ponto de referência para estudo do tema (SCHEFFLER, 2016a).

A partir de 2015 , o professor passou a trabaIhar diretamente junto ao departamento de Desenho Industrial. Propôs também uma nova disciplina optativa para o Bacharelado em Design: Corpo, forma, movimento (60h), que iniciou a primeira turma em 2017. A disciplina seguiu com caráter experimental na exploração das relações do corpo-movimento e a expressão do corpo com formas plásticas, consi-

6 O III Curso de Especialização em Cenografia formou 7 alunos. Teve 475 horas. O IV Curso de Especialização em Cenografia formou 10 alunos. Teve 370 horas.

7 A relevância destes três cursos em âmbito local se dá significativamente quando considerado que somente a partir de 2019, a cidade de Curitiba passou a contar com cursos stricto sensu em artes, junto à UNESPAR (exceção da Música, na UFPR, que é anterior). Em todas as turmas de Cenografia, houve alunos de outras cidades e outros estados. 
derando as implicações do movimento sobre a forma. Exploram-se processos criativos dinâmicos, a produção de imagens produzidas pelo corpo (pelo movimento e pelo uso de elementos materiais), representações do movimento, a cronofotografia e realizações teatrais feitas na Bauhaus. A disciplina envolve: consciência e expressão corporal, relações do corpo no espaço, desenho, fotografia, vídeo, imagens tecnológicas do corpo, escultura, colagem, adereços, máscaras e figurinos experimentais. Um fundamento para esta disciplina é o Laboratório de Estudo do Movimento, da Escola Internacional de Teatro Jacques Lecoq, na França.

Outra nova disciplina optativa também foi ofertada: Design teatral (60h). A proposta desta disciplina é abordar os elementos visuais cênicos e sonoros do teatro (cenografia teatral, figurino, maquiagem artística, iluminação cênica, teatro de formas animadas e sonoplastia) aplicando conhecimentos de design a conhecimentos teatrais. São desenvolvidos exercícios para entender cada um destes elementos, bem como os contextos de produção dos profissionais de design cênico. Como atividade culminante, foi proposto o desenvolvimento de projetos de teatro lambe-lambe. A dimensão reduzida permitia aos alunos uma prática teatral completa (e não apenas na formulação de um projeto) graças a sua dimensão. Estão incluídos processos de criação de dramaturgia e aplicados conhecimentos de design mobiliário, ergonomia, materiais, design de som entre outros.

Em 2013, foi criado o Projeto de Extensão Desenvolvimento da Cenografia (PEDC), aprovado pelo Edital do Programa de Extensão, da Secretaria de Ensino Superior, do Ministério da Educação (PRoExt 2013 - SESu/MEC), cujo financiamento proporcionou a formação de um grupo com 12 alunos bolsistas e mais 2 voluntários, de sete cursos de graduação diferentes da UTFPR (Design, Design Gráfico, Licenciatura em Letras, Comunicação Institucional, Arquitetura,
Educação Física e Engenharia Elétrica) ${ }^{8}$. Este grupo trabalhou junto ao TUT na produção do espetáculo Babel (texto e direção de Scheffler) na produção do cenário, figurino, maquiagem, iluminação, sonoplastia e materiais gráficos (SCHEFFLER, 2013b).

\section{Figura 1 - O espetáculo Babel foi apresentado em um galpão.}

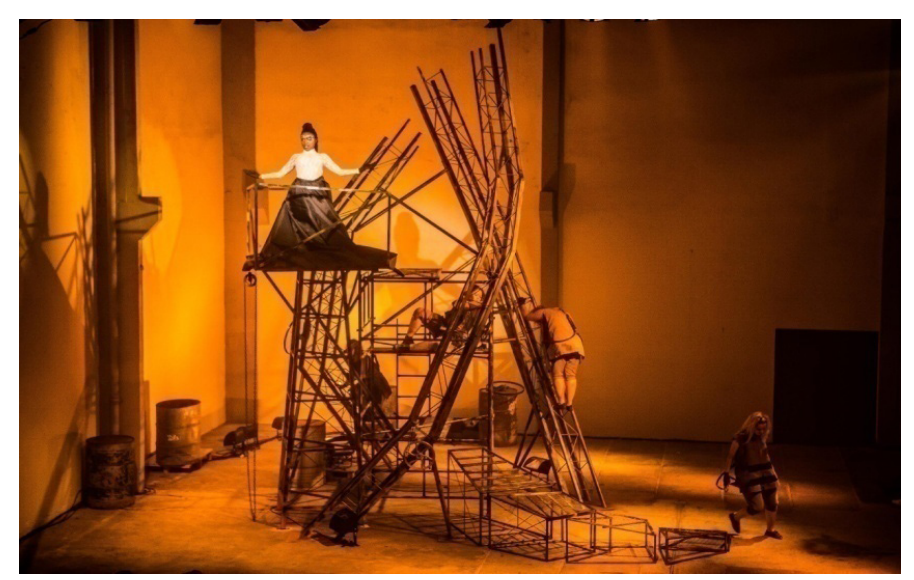

Foto: Studio Marios Bros.

Com recursos do edital, ainda foi realizado na UTFPR o I Seminário de Design Cênico: elementos visuais e sonoros da cena, em novembro 9 . Pesquisadores brasileiros de nove estados brasileiros participaram, tendo o cenógrafo francês Jean-Guy Lecat como conferencista convidado. Na programação desse evento, a Quadrienal de Praga encontrou seu primeiro espaço na UTFPR com a realização da mesa redonda Organizações nacionais e internacionais em performance design, composta por Nádia Luciani (PR), Rosane Muniz (SP), Aby Cohen (SP) e Jean-Guy Lecat (França). Dentre outros eventos

8 Alunos do I PEDC: Amanda Marciniak, Betina Bonilauri, Diogo Duda, Felipe Serenato Leal, Henrique Jakobi, Lívia Gariani, Jaqueline Modesto, Lua Volpi, Lucas Queiroz Morais, Luiz Ricardo Castro, Maria Lígia Freire, Mariana Garcia da Silva, Matheus Mayer, Natália Martins.

9 Comitê científico: Dra. Amábilis de Jesus da Silva e MSc. Nádia Moroz Luciani (FAP), MSc. Soraya Sugayama e do Dr. Walter Lima Torres Neto (UFPR), MSc. Ivone de Castro e Dr. Ismael Scheffler (UTFPR). 
internacionais, a PQ foi apresentada e discutida ${ }^{10}$. No segundo semestre de 2014, como extensão universitária, foi realizado o II Projeto de Extensão de Desenvolvimento da Cenografia, desta vez visando a participação na Quadrienal de Praga de 2015. De setembro a dezembro, sob as diretrizes fornecidas pela coordenadoria nacional, encabeçada pela professora Sônia Paiva, da Universidade de Brasília, foi organizado um projeto pedagógico de extensão com encontros presenciais semanais. O convite foi estendido aos alunos que haviam participado do PEDC que produziu Babel, aos alunos das turmas da disciplina Espaço Cenográfico e aos alunos da segunda turma da Especialização em Cenografia. Os quinze alunos se encontravam para reuniões semanais e foram organizados em três pequenos grupos para a elaboração de trabalhos.

A partir do tema Politics, vinculado ao tema da mostra Brasil: LABirintos compartilhados, os grupos foram orientados à experimentação corporal do espaço, a explorações bi e tridimensionais, considerando as relações dinâmicas entre formas, objetos e pessoas. Cada grupo escolheu uma música que serviu como texto motor para a criação, como um pré-texto dramatúrgico, resultando em propostas cenográficas que possibilitassem e induzissem interações políticas entre seus usuários. Os trabalhos elaborados se caracterizaram por oferecer possibilidades de utilização variadas, tendendo a instalações interativas, a um espaço performático e para o uso em um espetáculo em configuração espacial alternativa à estruturação frontal das salas tradicionais de espetáculo que separam palco e plateia. Dois grupos com alunos de graduação conseguiram concluir os trabalhos para serem enviados à seletiva nacional.

10 Também fez parte da programação do Seminário: Mona Magalhães (RJ), Soraya Sugayama (PR), Eduardo Tudella (BA), Luciana Bueno (SP), Ary Giordani (PR), José Sávio Oliveira de Araújo (UFRN), Ismael Scheffler (UTFPR), Paulo Biscaia Filho (FAP), Carlos Kur (PR), Alfredo Gomes Filho (PR), Cláudia de Bem (RS). A programação completa e os demais participantes podem ver conferidos nos Anais do evento disponíveis em: https:// issuu.com/ismaelssss/docs/anaisdoseminariodedesigncenico_06a0. Acesso em: 09 jul. 2020.
Cada um produziu um livro-objeto bilíngue, de acordo com as orientações dos organizadores nacionais. Os dois trabalhos propostos foram: Sinal fechado (música de Paulinho da Viola) ${ }^{11}$ e Dedo na ferida (música de Emicida) ${ }^{12}$.

\section{Figura 2 - Detalhe do livro-objeto} Sinal fechado.

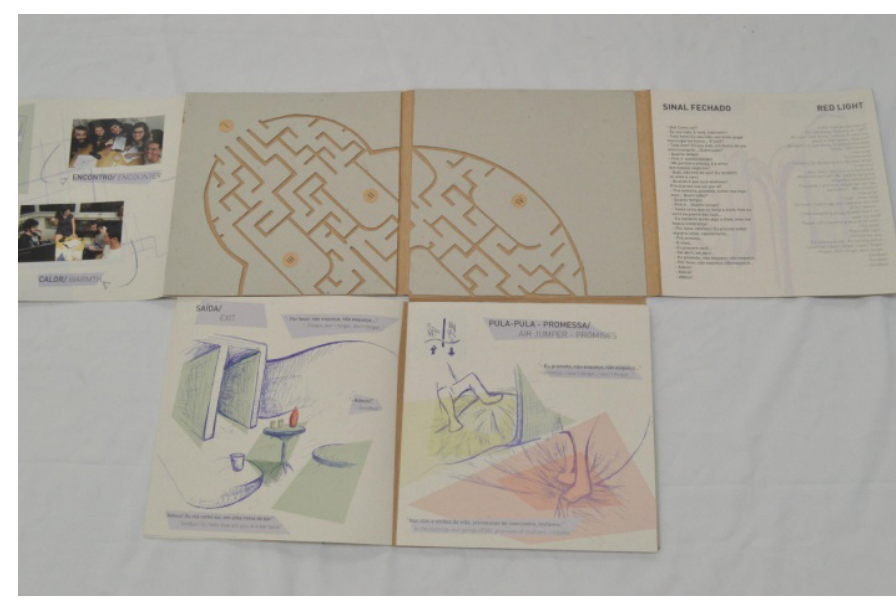

Foto: Arquivo pessoal, 2014.

Figura 3 - Detalhe do livro-objeto Dedo na ferida.

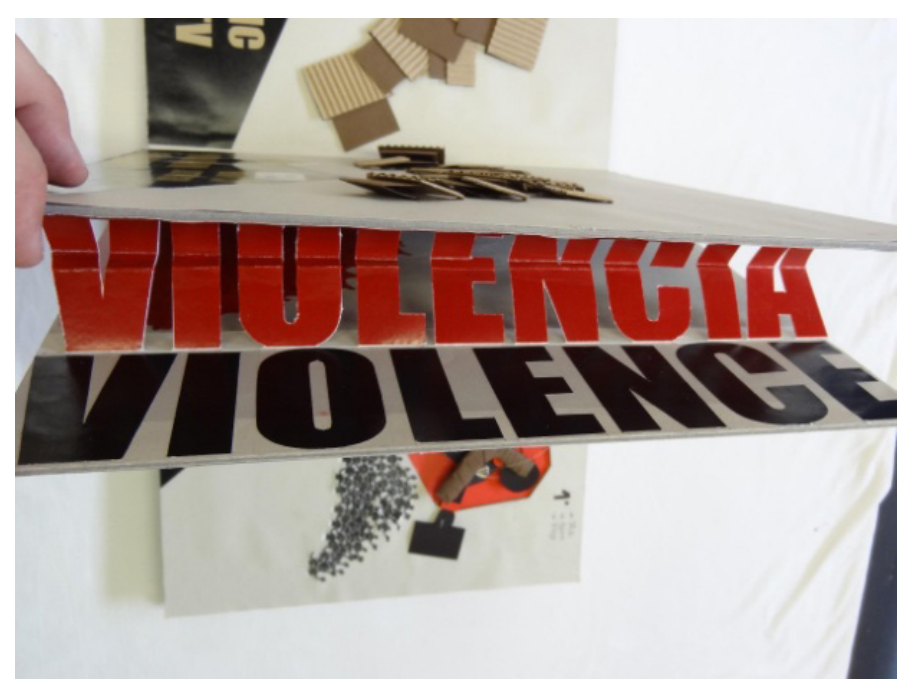

Foto: Arquivo pessoal, 2014.

11 Estudantes: Jonatas Carvalho, Maiara Donadoni, Maíra Fernandes Costa, Paulo Abreu (Bacharelado em Design) e Luiz Ricardo Gonçalves Castro (Bacharelado em Arquitetura);

12 Estudantes: Lucas Machado Rodrigues, Nathalya Reis Lackeski (Bacharelado em Design), Ana Carolina Lopes e Matheus Mayer (Bacharelado em Arquitetura). 
Os dois trabalhos foram expostos em Brasília no projeto Brasil: LABirintos compartilhados, em fevereiro de 2015. O evento contou com 68 projetos de 15 escolas $^{13}$, envolvendo 178 alunos e 41 professores orientadores. Sinal fechado ${ }^{14}$ foi selecionado e participou da Mostra das Escolas Brasileiras do Desenho da Cena, na República Tcheca.

No mês de agosto de 2015, logo após a Quadrienal realizada em Praga, foi organizada no Mini-auditório da UTFPR uma mesa-redonda com pessoas de Curitiba que estiveram na PQ daquele ano, entre artistas profissionais, professores, estudantes expositores e visitantes ${ }^{15}$. Além de relatos sobre as exposições, as discussões seguiram para análises dos conceitos implicados no evento, oferecendo difusão e debate atualizados no âmbito da capital paranaense, sob uma perspectiva múltipla local.

O II Seminário de Design Cênico: elementos visuais e sonoros da cena teve ocasião, na UTFPR, somente em junho de 2017, quatro anos depois do primeiro. O tema Ensino e Aprendizagens foi pro

13 UnB, UFSM, UFMG, UNESPAR/FAP, UTFPR, UFRJ, UNIRIO, CETIQT-SENAI, Escola São Paulo, Espaço Cenográfico de São Paulo, UNICAMP, Centro Universitário Belas Artes de São Paulo, USP, SP Escola de Teatro, UFRN (ROCHA, 2016).

14 Para ver imagens sobre o trabalho: https://www. behance.net/gallery/23343809/Livro-Sinal-Fechado. Acesso em: 09 jul. 2020.

15 Compuseram a mesa: Nadja Naira (iluminadora e expositora em Praga), Nádia Moroz Luciani (iluminadora, expositora em Praga, professora na FAP e parte do corpo docente da Especialização em Cenografia da UTFPR), Amábilis de Jesus (figurinista, professora na FAP e na Especialização em Cenografia), Levi Brandão (cenógrafo, diretor, músico e egresso da segunda turma da Especialização em Cenografia da UTFPR), Manuela Tourinho Orue (arquiteta e aluna no momento da terceira turma da Especialização em Cenografia), Giovana Kimak (arquiteta), Bianca Guimarães, Marcela Mancino e Guilherme Almeida (alunos de Teatro da FAP e expositores na Mostra das Escolas em Praga). posto como fio condutor das discussões ${ }^{16}$. Além de palestras, mesas redondas, fóruns abertos, apresentações artísticas, visitas técnicas em espaços culturais e exposição, foram apresentadas 30 pesquisas acadêmicas realizadas em cursos de pós-graduação e graduação de dez estados do país ${ }^{17}$, tendo como convidado Horácio Wainhaus, arquiteto e professor Titular Regular de Morfologia e professor Titular de Heurística na Facultad de Arquitectura, Diseño y Urbanismo (Universidade de Buenos Aires).

Também foi realizada a segunda reunião de organização da Mostra das Escolas para a PQ'19 (a primeira havia sido em abril, no Rio de Janeiro), tendo a participação de Aby Cohen (Curadora Nacional do Brasil para a PQ'19), Carolina Bassi, Luiz Henrique Sá e André Sanches (UNIRIO), Cassia Monteiro (UFRJ) (colaboradores para a PQ'19 - Mostra das Escolas); e Sônia Paiva (UnB) (Curadora da Mostra das Escolas na PQ'15)18.

\section{Projeto de vídeo para a Quadrienal de Praga de 2019: o Laboratório de Experimentação do Espaço}

Em outubro de 2018, a coordenação da Mostra dos Estudantes Brasileiros de Desenho da Performance a ser realizada na $14^{\mathrm{a}}$ Quadrienal de Praga, em 2019, promoveu o evento IMAGINA[trans]

16 O comitê científico contou com coordenação de Ismael Scheffler e Cássia Maria Monteiro, e com os professores Amábilis de Jesus da Silva (UNESPAR/FAP), Nádia Luciani Moroz (UNESPAR/FAP), Mônica Magalhães (UNIRIO), José Sávio de Araújo de Oliveira (UFRN).

17 UNIRIO, UFU, UFRN, UFRGS, USP, FAP, UFRB, UTFPR, UNB, UFG, Anhambi-Morumbi, UFOP, UDESC, UFRJ, UNIMONTES.

18 Também fez parte da programação do Seminário: Sávio Araújo (UFRN); Berilo Luigi Deiro Nosella (UFSJ), Carlos Alberto Nunes da Cunha (UNIRIO), Amábilis de Jesus (UNESPAR-FAP); Chico Machado (UFRGS), Sérgio Izidoro (PR). A programação completa e os demais participantes podem ver conferidos nos Anais do evento disponíveis em: https://issuu.com/ismaelssss/docs/anais_ do_ii_semin_rio_de_design_c_nico_utfpr_2017. Acesso em: 09 jul. 2020. 
forma[inter]ação, realizado no Rio de Janeiro. Lá foram expostos os trabalhos a serem selecionados para compor a representação brasileira, bem como foram realizadas oficinas, performances, mesas redondas, debates e compartilhamentos pedagógicos.

Pela segunda edição consecutiva, a UTFPR integrou a Mostra dos Estudantes. Dentre as diferentes categorias propostas, a opção de participação foi pela [fala]AÇÃO que possibilitava o compartilhamento de metodologias de trabalho por audiovisual. A pergunta de motivação era: "O que você considera fundamental na formação artística no desenho da cena?".

Atendendo ao formato de vídeo de até sete minutos, Scheffler propôs a realização de uma aula-demonstração. A atividade foi realizada especialmente para a filmagem, em junho de 2018, no Auditório da UTFPR. Participaram das atividades os alunos Ana Gláucia de S. Vieira, Bruno Azzani Braga, Ettore Hadas Tasca, Gabriela Ingrid de Lima, Gabrielle Frigotto Ramos e Luísa Petrorossi Wolff dos Santos Lima de quatro diferentes cursos da UTFPR: Tecnologia em Design Gráfico, Bacharelado em Design, Arquitetura e Urbanismo e Especialização em Artes Híbridas. Estes alunos tomaram contato com a metodologia proposta pela primeira vez na vivência realizada. Um grupo eclético foi reunido especialmente para a produção do documentário ${ }^{19}$.

As imagens foram registradas pelos alunos lan Lages Coelho, João Conrado Sant $\square$ Ana de Lima Dembiski e João Victor Tarran Araújo, sendo a edição e trilha sonora da aluna Isabel Pimentel Palacio Garcia, todos alunos de De-

19 A relação dos alunos com Scheffler anterior a este dia era diversa, bem como o momento de cada um em sua trajetória acadêmica: Ana Gláucia havia cursado a disciplina Criatividade e Corpo, forma, movimento e estava no início de sua graduação em Tecnologia em Design Gráfico; Gabriela e Gabrielle cursaram com Scheffler a disciplina Espaço Cenográfico, e estavam concluindo Arquitetura; Ettore, havia cursado Criatividade e Corpo, forma e movimento no Bacharelado em Design e também Teatro e Hibridismos, na Especialização em Artes Híbridas, ambos na UTFPR; Luiza, também havia tido aula na mesma especialização (havia cursado Moda, anteriormente) e tinha experiência com teatro; Bruno, de Tecnologia em Design Gráfico, nunca havia tido aula com Scheffler. $\operatorname{sign}^{20}$. O roteiro, apresentação e direção foram do professor Ismael Scheffler (PATIRE, 2019).

A aula-demonstração teve duração de aproximadamente três horas abarcando uma seleção de exercícios que pudessem, no seu todo, apresentar alguns pressupostos da disciplina Laboratório de Experimentação do Espaço, desenvolvida por Scheffler na Especialização em Cenografia. Foi dada ênfase às atividades corporais, não correspondendo o vídeo, portanto, a todos aspectos desenvolvidos na disciplina, deixando-se diversas atividades plásticas de fora da vivência e registro. Optou-se por este recorte para em razão da limitação de tempo do vídeo final proposto no edital.

Foi um desafio realizar, mesmo que de maneira acelerada, uma sequência de exercícios em tão pouco tempo e de forma tão intensa. Mas, foi proposto que, apesar da prática pedagógica ser uma demonstração realizada para a filmagem, ela deveria ter coerência, ser realizada em determinada sequência e atingir o resultado esperado, pois como se trata de um processo, os alunos precisariam ter crescimento para as etapas seguintes.

Para a aula-demonstração, o professor havia traçado um planejamento e os registros foram sendo estabelecidos, definindo-se posição de câmeras e enquadramentos durante a vivência. Foi após as filmagens, na análise do material captado, que o roteiro e texto narrativo foram definidos. A duração máxima do vídeo era predeterminada pela organização da mostra e sintetizar a vivência em sete minutos foi um grande desafio. A seleção e edição das imagens resultaram de um dedicado trabalho de Palacio e Scheffler.

A disciplina Laboratório de Experimentação do Espaço foi elaborada consoante a vários aspectos da proposta pedagógica do Laboratório de Estudo do Movimento (LEM) da escola de teatro de Jacques Lecoq (SCHEFFLER, 2012; 2013a; 2019). Foi proposta na grade curricular da segunda turma da Especialização em Cenografia

20 Os três rapazes haviam cursado Criatividade, com Scheffler, e Isabel havia feito a disciplina Corpo, forma e movimento. 
(2013), e novamente nas turmas de 2015 e 2017. A disciplina Laboratório de Experimentação do Espaço teve variações: na primeira edição teve 20 horas (complementada por mais 20 horas na disciplina Atelier de criação plástica), na segunda teve 40 horas (que unificou os trabalhos), na terceira, novamente 20 (houve redução significativa da carga horária do curso como um todo). No projeto para a turma de 2019 (que não chegou a ser realizado), estava prevista com 30 horas $^{21}$. Estas variações têm a ver, especialmente, com a maneira como era previsto articular a disciplina de Composição visual (ou Atelier de criação plástica), uma vez que elas acionavam alguns conteúdos em comum por metodologias ou suportes distintos, bem como em razão de reestruturação financeira do curso.

Um dos objetivos deste curso de especialização era a inclusão de atividades práticas por meio de laboratórios e ateliês possibilitando ao aluno experimentar. O perfil principal dos alunos da Especialização em Cenografia em suas diferentes turmas na UTFPR foi de pessoas graduadas em Arquitetura, Artes Visuais e Design (além de outros cursos) que possuem pouca ou nenhuma familiaridade com a cena (tendo também alunos graduados em teatro ou com experiência na área).

Para alunos oriundos do meio teatral, no qual o trabalho com o corpo tem relativa familiaridade, a abordagem perpassa por uma mudança de foco: em geral, o trabalho de expressão corporal realizado na graduação está voltado para o trabalho atoral (na formação de profissionais ou voltado à educação pelo teatro), envolvendo consciência do corpo e seus movimentos para a criação de personagens, cenas ou improvisações. Na abordagem da disciplina, o foco está sobre o espaço, sendo o trabalho corporal o meio para compreendê-lo.

21 Ementa: "O corpo no espaço. Percepção sensível do ambiente. Níveis do corpo e do espaço. O espaço dinâmico. O centro e a periferia. Dinâmica espacial das paixões. Representação plástica das pesquisas corporais e espaciais. O método mimodinâmico e suas possibilidades criativas. Composição em cenografia: equilíbrio, ritmo, dinâmica, movimento."
Para alunos com graduação pautada em projetos e criações sobre suportes como o papel ou a tela do computador, o envolvimento em um trabalho corporal corresponde muitas vezes ao rompimento de paradigmas. O corpo bloqueado, o corpo tímido ou o corpo alienado por vezes evidencia-se e impõe dificuldades significativamente de ordem psico-social e, por consequência, também pedagógica. $O$ trabalho corresponde a uma ação sobre atitudes para o desenvolvimento de uma sensibilização dos sentidos e uma compreensão do espaço pela experiência do corpo e suas relações com outros corpos (humanos, objetos ou elementos da natureza ou arquitetura).

Subsidiar a pesquisa sobre cenografia ou colaborar para a formação de cenógrafos implica em problematizar a atuação do cenógrafo. "Ensinar criatividade" demanda o desenvolvimento de atitudes e posturas. Pensar o espaço para a cena e para o usuário exige pensá-lo internamente além de para o olhar externo.

A experiência corporal para cenógrafos possibilita uma aproximação ao trabalho do ator, já que passa a explorar o movimento e o espaço pela vivência direta. Alguns aspectos que parecem ser importantes para atender as novas demandas do trabalho do cenógrafo em produções teatrais perpassam pela ênfase na percepção do espaço e das construções arquitetônicas, em suas propriedades, em seus aspectos orgânicos (e não meramente geométricos, matemáticos ou mecânicos), nas dinâmicas e nos impactos dos espaços sobre o ser humano, na maneira como o(s) corpo(s) reage $(\mathrm{m})$ e se (re) $\operatorname{organiza}(m)$ e como as relações interpessoais se estabelecem. Pode-se estabelecer certa relação com a Sintaxe Espacial (ou Teoria da Lógica Social do Espaço), desenvolvida por Bill Hillier (HILLIER; HANSON, 1984) para analisar as configurações urbanas.

Perceber sensivelmente o implícito do espaço e não apenas os enunciados racionais (as explicações atribuídas conscientemente) permite ver relações intrínsecas de âmbito sintático e não apenas o semântico. Estar sensivelmente atento às induções e provocações dos entornos é desafio a um trabalho de formação que suplanta projetos que não dialo- 
gam com o meio no qual pretendem se inserir. $\mathrm{O}$ objetivo pedagógico principal deste tipo de improvisação é de utilizá-la como uma ferramenta analítica para entender o espaço, as relações espaciais e o jogo do olhar, não sendo, a princípio, uma ferramenta de aplicação direta para projetar cenários.

Diversos aspectos desta proposta também foram empregados nos projetos de extensão de produção do espetáculo Babel e no processo criativo que levou a produção dos livros-objetos para a PQ'15. Assim como nas três disciplinas oferecidas na graduação de Design são utilizados alguns exercícios como a pesquisa corporal e a improvisação cenográfica em escala natural, por exemplo.

Além da significativa influência do LEM sobre esta proposta de ensino-aprendizagem, também há instigação (em diferentes proporções) em Scheffler de dois encenadores e professores: Antônio Araújo (USP), que ministrou a disciplina Apropriação e memória da arquitetura (20h), na primeira turma de Especialização em Cenografia, em 2009, que foi acompanhada por Scheffler como ouvinte; e André Carreira (UDESC), com quem Scheffler teve aulas, principalmente no campo teórico, na pós-graduação ${ }^{22}$. Ambos são pesquisadores sobre o espaço no teatro e desenvolvem estudos sobre a dramaturgia do espaço.

A metodologia ativa proposta considera o aluno como construtor do conhecimento pela experimentação direta. Há, portanto, um fundamento na Escola Nova e nos estudos da fenomenologia do alemão Edmund Husserl. O trabalho perpassa pelo desenvolvimento da propriocepção, pautado em um sistema autorreferente da espacialidade. É vivenciando pelo corpo em movimento que o aluno desenvolve a percepção das ações em uma dimensão consciente (senciência), buscando um acesso intencional do mundo, realizando ações atentamente para, posteriormente, realizar a descrição dos padrões percebi-

22 Araújo tomou exercícios que empregava na formação de atores e diretores propondo-os para a formação de cenógrafos em exercícios corporais variados. Scheffler foi aluno de Carreira no Curso de Especialização em Teatro da FAP (2001) e no Programa de Pós-Graduação em Teatro (UDESC), no Mestrado (2002) e Doutorado (2009). dos. Estas constatações não são, portanto, opiniões, mas observações das construções dos referentes espaciais do fluxo vivido. Explora-se, além da noção de espaço próprio, relações hápticas do espaço e o peri-espaço (CASTRO; GOMES, 2011), estabelecendo-se relações com a Filosofia Ecológica e a noção de affordance de James J. Gibson (LARGE, 2011).

Pode-se encontrar amparo teórico também nos estudos de: Maurice Merleau-Ponty (Fenomenologia da percepção (1999)); Marcel Jousse (em L'anthropologie du geste (2008)); Gaston Bachelard (2008), em aspectos que repercutem na ideia da empatia estética, também presente em Rudolf Arnheim (Arte e percepção visual: uma psicologia da visão criadora (1997)), na atribuição de expressão a padrões estruturais percebidos (Psicologia da Gestalt); e em Edward T. Hall (A dimensão oculta (2005)), sobre as implicações da cultura na percepção sensorial e nas zonas de distância nas inter-relações pessoais.

\section{Improvisação cenográfica em escala natural $(1: 1)$}

A improvisação cenográfica em escala natural difere de metodologias projetuais bi ou tridimensionais em escala reduzida. É uma proposta metodológica para a formação de cenógrafos que compreende o exercício rápido de composição cenográfica direta, isto é, pela construção volumétrica em escala natural (1:1), cujo o tamanho físico do objeto coincide com o tamanho real estando seus construtores dentro do próprio espaço.

Um exercício compositivo foi proposto no LEM, vivenciado por Scheffler (2013a) enquanto aluno (turma 2010-2011), no qual, em uma grande sala, em grupos, os alunos tomando objetos existentes no ambiente criavam composições dispondo os objetos procurando estabelecer entre eles diferentes relações de força pela aproximação e distanciamento, movendo um objeto por vez e se deslocando pela área delimitada para o experimento. Após improvisações livres, cada grupo sistematizou cinco composições para serem apresentadas (como fotos estáticas) em 
sequência de maneira frontal (com área separada da audiência e da cena). Dessas dinâmicas se pode perceber como as relações entre os objetos conduz a diferentes estados de tensão e inter-relação, o que vai gerando narrativas/ dramaturgias visuais.

\section{Figura 4 - Improvisação compositiva com objetos} experimentando relações de tensão e ritmo no LEM, em 2011.

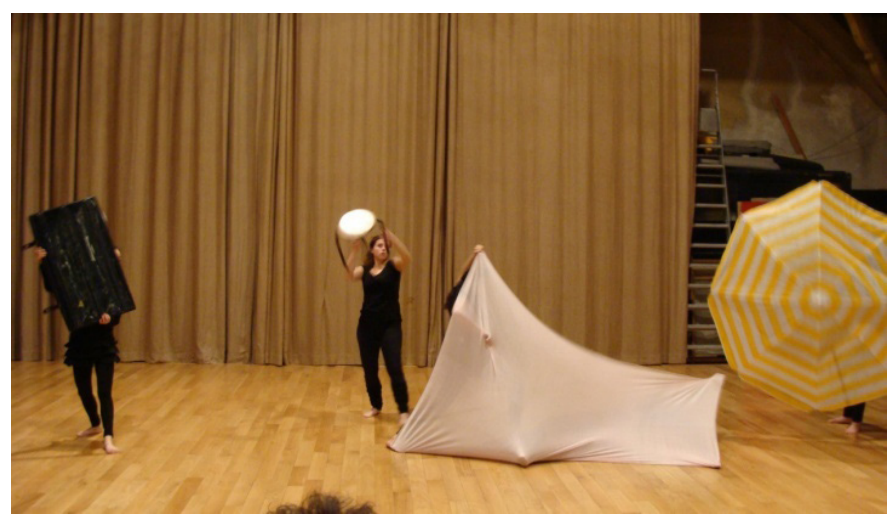

Fonte: Arquivo pessoal, 2011.

Outro exercício nessa linha foi a realização de construções ligadas a pesquisa sobre o espaço de movimento das paixões humanas, que corresponde a uma análise sintática espacial. Uma prática recorrente do LEM é a transposição: após a pesquisa de determinado tema pelo movimento do corpo no espaço (método mimodinâmico), o tema pesquisado é transposto em linguagens plásticas bi ou tridimensionais utilizando-se materiais simples (papel, cartão, palitos de madeira, tinta, arame, argila, entre outros) ou ainda em escala arquitetural (ver SCHEFFLER, 2013a; 2019). Há um aspecto sistêmico atrelado a isto. Assim, após serem trabalhadas diferentes paixões humanas em movimento, se propôs a construção de um percurso de paixões ou estados utilizando objetos da sala (todo tipo de mobiliário ou objetos) em um trajeto a ser percorrido pelas pessoas (sem dar explicações ou orientações) e levar o visitante a vivenciar a dinâmica daquelas paixões fisicamente.
Figura 5 - Construção realizada na transposição de dinâmicas espaciais das paixões com objetos no LEM, em 2011.

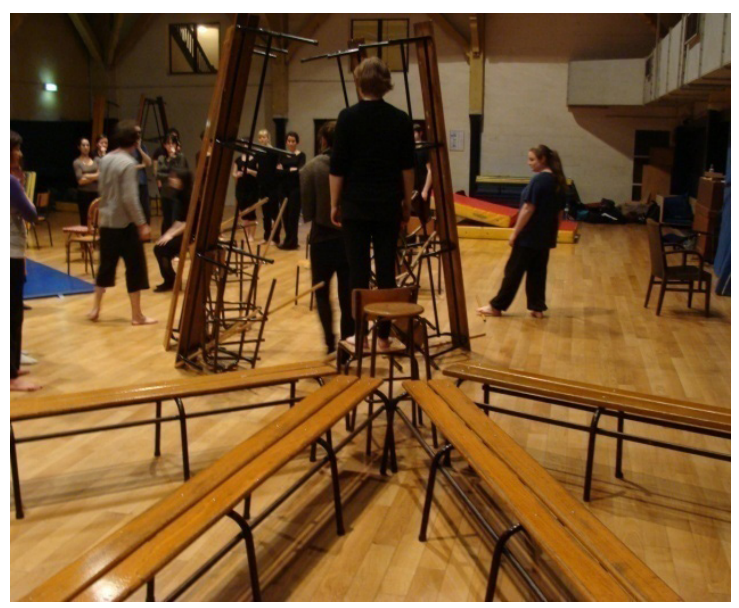

Fonte: Arquivo pessoal (2011).

Uma necessidade dessas propostas é ter disponíveis objetos variados em tamanhos, materiais e estruturas bem como haver também um ambiente com dimensões para conter os objetos que estão sendo usados e os sem uso.

A opção por caixas de papelão desmontáveis é uma alternativa viável por serem volumes de fácil manuseio, economicamente mais acessíveis e fáceis de serem armazenadas após o uso ${ }^{23}$. Elas oferecem a possibilidade de construções volumétricas e empiIhamentos, tendo estrutura e revestimento. Por existir em diferentes dimensões, permite combinações variadas (possui semelhança a jogos infantis de blocos de madeira ${ }^{24}$. Por ter coloração única, colabora no

23 A cenógrafa brasileira Vera Hamburger parece desenvolver uma prática pedagógica que possui concepções possíveis de serem correlacionadas. No entanto, não há influências entre Hambuger e Scheffler. Há alguns anos, a visualização de uma foto na internet de uma oficina de Hamburger utilizando caixas de papelão despertou Scheffler à percepção da potência deste material como alternativa à utilização de objetos e mobiliários diversos como utilizados nas atividades descritas no LEM.

24 Há limitações do material. Utilizar as caixas abertas traz bastante instabilidade ao objeto. Também não permite que, na exploração do corpo se suba nos materiais, o que limita e pesquisa na percepção das relações verticais. 0 trabalho compositivo de cores fica dirigido a estudos com luz e em suporte bidimensional. 
direcionamento do foco para a exploração do espaço e a percepção sobre a luz e não condiciona a percepção significativamente para diferenças de cores.

Os exercícios propostos na UTFPR têm variações na provocação compositiva. O ato improvisacional (mais imediato ou mais elaborado) traz o desafio de resolução de problema de forma rápida e o ato projetual menos comprometido com detalhamento e resoluções verificadas amplamente. Quando proposto simplesmente que se construa algo no palco com as caixas sem qualquer outra orientação, não é incomum a produção de uma estrutura unitária (monolítica) centralizada, ou uma composição simétrica, ou manifesta a preocupação com alinhamentos regulares (aspectos de ritmo, equilíbrio e harmonia em composições de maior simplicidade). Reconhecer estes condicionamentos visuais é importante para que se busquem composições mais complexas.

A verificação dos deslocamentos com o corpo nestes espaços evidencia como o ser humano tende a se mover nesses tipos de estruturas pelas linhas axiais.

É possível lançar desafios criativos com diferentes princípios. Algumas vezes é sugerida a criação simples de divisões no espaço, propondo circuitos com diferentes dinâmicas com variações de dimensões, de distância, fluxos e organização entre os elementos de forma a provocar e empenhar o corpo do usuário. Outras vezes são solicitadas composições dinâmicas dotadas de movimento visual. Ou ainda, que se construa a partir de temas (como: o naufrágio, o vento, a força, a ordem, a festa). As possibilidades podem ser muitas.
Figura 6 - Improvisação cenográfica em escala

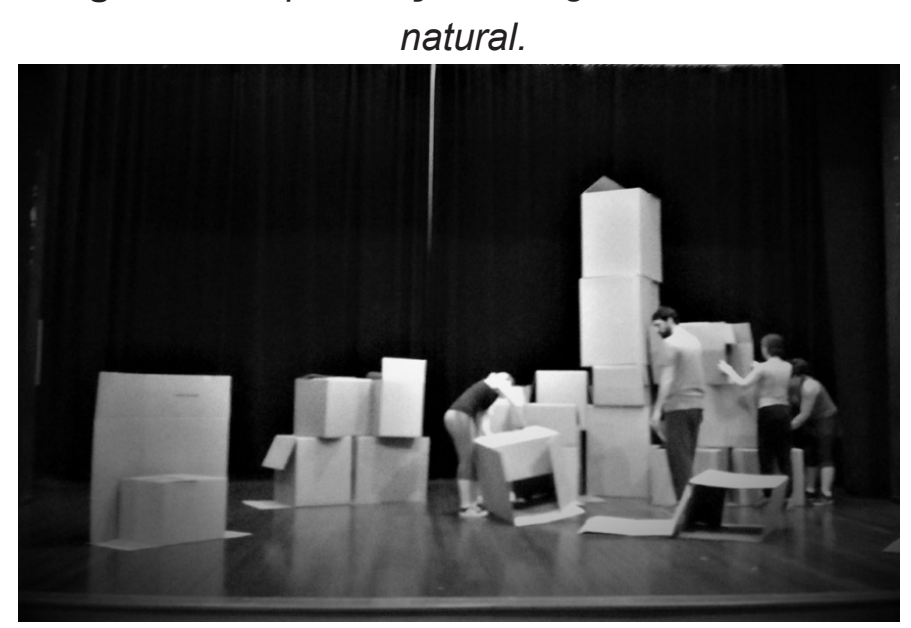

Foto: Arquivo pessoal.

O objetivo da proposta pedagógica é também possibilitar que o aluno entenda como é habitar o espaço, como é estar no lugar feito para o ator (neste aspecto há correspondência com a Teoria da Lógica Social do Espaço). Esta metodologia visa oferecer uma vivência corporal e de palco aos alunos que aprendem a ver o espaço por dentro, sentir o espaço, perceber como o espaço induz o corpo e como a forma do corpo, sua posição do espaço e seus deslocamentos expressam diferentes relações e fazem surgir dramaturgias.

Tendo vivenciado e desenvolvido uma sensibilização prévia sobre o espaço, um repertório de aspectos já identificados constitui um rol de itens (sistematizados) a serem averiguados, o que permite fazer constatações a partir do uso de cada estrutura produzida. O aluno então precisa se movimentar e se deslocar pela composição criada observando como a distribuição dos elementos influencia o corpo e como distintos pontos no espaço mudam a percepção de todo contexto. Ao percorrer o ambiente, o aluno verifica hierarquizações a partir da estruturação, percebe possibilidades de deslocamentos, fluxos, ritmos, entradas e saídas, ocultamentos, aparições, submissões do corpo ao se curvar, ao se erguer, ao subir, ao penetrar.

Um ambiente que tem se mostrado interessante para esta prática é o palco frontal no auditório da UTFPR. Dadas suas dimen- 
sões $(9,2 \mathrm{~m} \times 8 \mathrm{~m} \times 4,7 \mathrm{~m})$ oferece boas possibilidades para a manipulação desses materiais.

$O$ trabalho em um palco frontal determina o estabelecimento de uma frente de referência em relação à qual se dá o jogo da cena. Este pressuposto ajuda a entender uma concepção de espetáculo (daquele que é feito para ser visto externamente) diferente da experiência vivencial interna. Se em um primeiro momento o jogo se dava entre os agentes internos, a definição de um observador externo traz novos elementos a serem pesquisados. É no estabelecimento deste ponto de vista que se define a frente e o fundo do palco, se passa a ter outros princípios de hierarquização das áreas do palco, reconsiderando-se as linhas de força que se estabeleceram nas divisões, jogando-se com a sensação da presença do observador e estabelecendo provocações físicas entre atores-espectadores.

Em certo sentido, se experimenta algo que Jacinto Lageira (2011) distingue em relação à obra de arte: experiências estéticas de domínio do háptico (na relação direta do corpo que vivencia na pele) e as experiências ópticas (que necessitam da imaginação que toma as sensações vividas anteriores para dar sentido ao que se vê).

A utilização de fontes luminosas (refletores) permite perceber a modelagem e reconfiguração da construção feita de improviso. Contribui para que o aluno perceba as possibilidades tridimensionais que o palco tradicional frontal oferece e assim tornar as composições cenográficas mais ricas e dinâmicas. A luz direcionada faz ver sombra e redesenha a percepção do espaço evidenciando aspectos não observados, redimensionando toda composição. As variáveis de equipamentos, tipos de luz, intensidade, cores e uso de projeções trazem diferentes camadas para pensar cenário e iluminação. A manipulação de refletores, mudando-os de posição com facilidade, contribui da mesma maneira que a manipulação das caixas para novas resoluções e testes, averiguando hipóteses e aprendendo pela experiência direta.
Figura 7 - A luz tem possibilidade de reconfigurar mesmo estruturas simétricas.

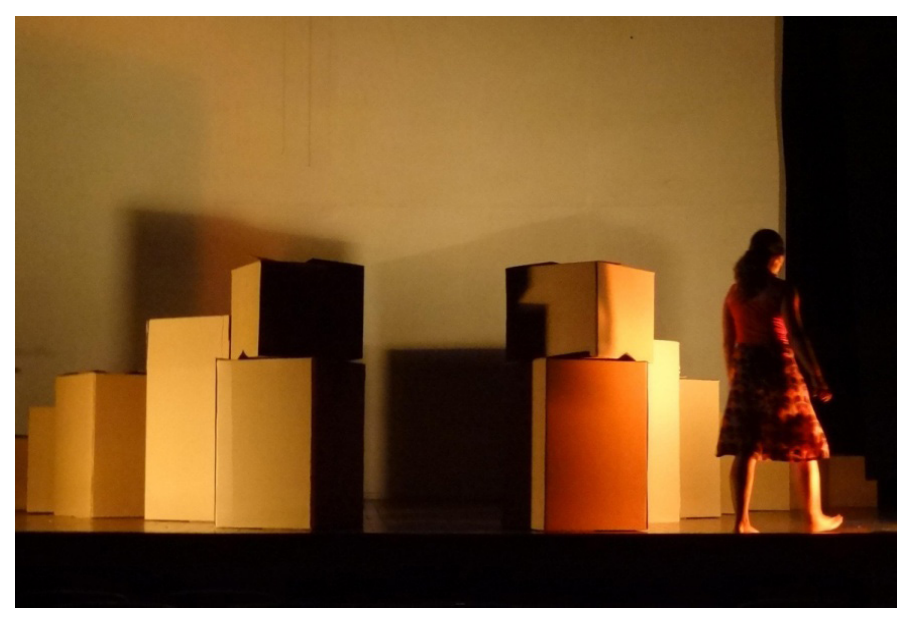

Foto: Arquivo pessoal.

Há, nessa linha, uma percepção interna do espaço, da construção, da luz. Mas ao se percorrer diferentes áreas da plateia olhando para o palco, se passa a realizar o olhar externo do espectador. Circular livremente pela sala vendo a mesma composição de diferentes pontos, mais próximos ou mais distantes, mais laterais ou mais centrais, ajuda a perceber as implicações para o público (e tira o condicionante idealizado pela perspectiva de pensar o cenário apenas do ponto ideal do espectador centralizado na plateia e o "olhar do príncipe" da perspectiva linear).

$O$ registro em fotografias canaliza mais uma maneira de aprender a ver e a compor, sendo um recurso rico que ajuda a enquadrar o olhar e a conhecer possibilidades da fotografia de espetáculos.

O registro gráfico pelo desenho de croquis se torna um exercício do olhar atento de outra ordem. O processo de abstrair o espaço construído e vivenciado contribui para a percepção da coerência da escala entre os elementos, das proporções, das distâncias e das diferenças entre o que se construiu para habitar e o efeito que provoca ao olhar externo.

$\mathrm{O}$ croqui rápido da perspectiva também pode servir de base para estudos diversos, como sobre a volumetria, dando sentido dramático aos volumes ou tematizando a forma. A partir de croquis também é possível experimentar composições de cores, perce- 
bendo como visualmente elas podem influenciar nas alterações de percepção de dimensão, proporção, peso, ritmo e hierarquizações dos diferentes módulos.

$\mathrm{Na}$ realização da perspectiva e da planta baixa, surge a compreensão da importância de cada uma dessas representações que oferecem elementos distintos para entender e registrar 0 espaço e a imagem criada e, por conseguinte, também para projetar em âmbito bidimensional.

\section{Considerações finais}

O estudo da cenografia na UTFPR tem buscado estabelecer conexões e parcerias para potencializar e viabilizar ações. Estas têm sido realizadas significativamente em projetos de extensão, bem como em disciplinas optativas da graduação de Design, mas também em nível de pós-graduação lato sensu.

No âmbito da UTFPR, a cenografia e a Quadrienal de Praga possuem abordagens e significações peculiares que se articulam entre o teatro, o design, a arquitetura e engenharias, com alunos interessados em múltiplas áreas profissionais que vão além do mercado artístico.

A formação de Scheffler em direção teatral com significativa prática em teatro estudantil influencia as discussões de cenografia em uma perspectiva voltada à encenação, ao uso e à vivência do espaço, seja pelos atores, pelas relações entre espectadores e cena, por visitantes de exposições ou por usuários diversos, seja vendo externamente ou experimentando internamente.

Para o teatro, para o design ou para a arquitetura, a dissolução de campos e a habitação em áreas ecótonas parece se apresentar como desafio de imensas possibilidades nos processos de ensino-aprendizagem e para realizações profissionais. Tendência esta que parece ser o objeto que as curadorias gerais da Quadrienal de Praga também têm, de certa forma, problematizado nos últimos tempos.

Talvez uma perspectiva interessante para se considerar a respeito da Quadrienal de Praga é como ela provoca movimentos para além do even- to em si. A despeito de sua grandiosidade e relevância, diversas reverberações ocorrem em níveis variados provocando fluxos em encontros, debates, reflexões, práticas e sínteses de processos. É, nesta compreensão, que o presente texto procurou apresentar aspectos entre a $P Q$ e a UTFPR.

No que tange ao tema exposto no documentário produzido e aqui ampliado, a ideia de "improvisar" cenografia em escala natural não é nova, como já apontado. Mas este tem sido um tema instigante de abordagem alternativa como prática pedagógica que parece poder contribuir a múltiplos interesses em torno da cenografia.

Parece ainda haver muito a ser considerado a partir dos estudos fenomenológicos, da psicologia da Gestalt e da Filosofia Ecológica tanto na formação em teatro quanto em design e arquitetura (sem distinguir funções ou profissões específicas), pois estes estudos oferecem reflexões instigantes e desafiadoras.

\section{Referências}

ANAIS do Seminário de Design Cênico: elementos visuais e sonoros da cena. 06 a 09 de novembro de 2013. v. 1, n. 1. Curitiba: UTFPR, 2013. Disponível em: < https://issuu.com/ismaelssss/docs/anaisdoseminariodedesigncenico_06a0 > . Acesso em: 15 jun. 2020.

ANAIS do I/ Seminário de Design Cênico: elementos visuais e sonoros da cena. 31 de maio a 03 de junho de 2017. v. 2, n. 1. Curitiba: UTFPR, 2017. Disponível em: < https://issuu.com/ismaelssss/docs/anais_ do_ii_semin_rio_de_design_c_nico_utfpr_2017 >. Acesso em: 15 jun. 2020.

ARNHEIM, Rudolf. Arte e percepção visual: uma psicologia da visão criadora. São Paulo: Pioneira, 1997.

BACHELARD, Gaston. A psicanálise do fogo. 3a. ed. São Paulo: Martins Fontes, 2008. 
CASTRO, Thiago Gomes de; GOMES, Willian Barbosa. "Como sei que eu sou eu?": cinestesia e espacialidade nas conferências husserlianas de 1907 e em pesquisas neurocientíficas. Revista da Abordagem Gestáltica. v. 17, n. 2, p. 123-130, jul-dez, 2011. Disponível em: < http://pepsic.bvsalud.org/scielo.php?script=sci_arttext\&pid=S1809-68672011000200002 > . Acesso em: 01 mai. 2020.

COHEN, Miriam A. Cenografia brasileira século XXI: diálogos possíveis entre a prática e o ensino. 2007. 198 f. Dissertação (Mestrado em Artes) - Escola de Comunicação e Artes, Universidade de São Paulo, São Paulo, 2007. Disponível em: < https://teses. usp.br/teses/disponiveis/27/27139/tde-17102007090756/pt-br.php >. Acesso em: 15 jun. 2020.

HALL, Edward T. A dimensão oculta. São Paulo: Martins Fontes, 2005.

HILLIER, Bill; HANSON, Julienne. The Social Logic of Space. Cambridge: Cambridge University Press, 1984.

JOUSSE, Marcel. L'anthropologie du geste. Paris: Gallimard, 2008.

KOSOVSKI, Lídia; MARÉS, Fernando. Espaço Cênico: Estudantes de todo Brasil na Quadrinal de Praga/ PQ 07. Revista Luz \& Cena. 14/06/2007. Disponível em: < http://www.musitec.com.br/luzecena/revista_ artigo.asp? revistalD=2\&edicaolD=95\&nav $I D=2409$ >. Acesso em: 01 mai. 2020.

LAGEIRA, Jacinto. Uma experiência peculiar. Revista-Valise, Porto Alegre, v. 1, n. 1, ano 1, julho de 2011, p. 9-13. Disponível em: < https://seer.ufrgs.br/ RevistaValise/article/view/22051/12807 >. Acesso em: 15 jun. 2020.
LARGE, David. O que é Filosofia Ecológica. Trad.: Juliana Moroni; Maria Eunice Quilici Gonzalez; João Antonio de Moraes. Kínesis - Revista de Estudos dos Pós-Graduandos em Filosofia, v. 3, n. 05, jul. 2011, p. 349-355. Disponível em: < https://revistas. marilia.unesp.br/index.php/kinesis/article/view/4414 >. Acesso em: 01 mai. 2020.

MERLEAU-PONTY, Maurice. Fenomenologia da percepção. 2a. ed. São Paulo: Martins Fontes, 1999.

NOVO curso de Cenografia da Escola Técnica está com inscrições abertas. Superintendência de Comunicação Social, UFPR. 05 de outubro de 2006. Disponível em: < https://www.ufpr.br/portalufpr/noticias/ novo-curso-de-cenografia-da-escola-tecnica-esta-com-inscricoes-abertas/ >. Acesso em: 10 jun. 2020.

PATIRE, Daniel. UTFPR representa o Brasil na Quadrienal de Praga 2019. Paranashop. 19/06/2019. Disponível em: < https://paranashop.com.br/2019/06/ utfpr-representa-o-brasil-na-quadrienal-de-praga-2019/ >. Acesso em: 01 mai. 2020.

ROCHA, Rosane Muniz. Um panorama do traje teatral brasileiro na Quadrienal de Praga (1967-2015). 2016. 591 f. 2 v. Tese (Doutorado) " Programa de Pós-Graduação em Artes Cênicas " Escola de Comunicações e Artes. Universidade de São Paulo, São Paulo, 2016. Disponível em: < https://www.teses. usp.br/teses/disponiveis/27/27156/tde-22092016153159/pt-br.php >. Acesso em: 01 mai. 2020.

SCHEFFLER, Ismael. TUT, TECEFET, TETEF: 35 anos de teatro na Universidade Tecnológica Federal do Paraná. Curitiba: UTFPR, 2008. 
SCHEFFLER, Ismael. O Laboratório de Estudo do Movimento da Escola Internacional de Teatro Jacques Lecoq. Anais do VII Congresso da Abrace $\square$ Associação Brasileira de Pesquisas e Pós-graduação em Artes Cênicas, 08 a 11 de outubro de 2012, Porto Alegre, RS, v. 13, n. 1, 2012. Disponível em: < https:// www.publionline.iar.unicamp.br/index.php/abrace/article/view/2496/2630 >. Acesso em: 01 mai. 2020.

SCHEFFLER, Ismael. O Laboratório de Estudo do Movimento e o percurso de formação de Jacques Lecoq. 2013a. 591 f. 2. v. Tese (Doutorado em Teatro) - Universidade do Estado de Santa Catarina, Programa de Pós-Graduação em Teatro, 2013a.

SCHEFFLER, Ismael. (org.). Babel: o processo de criação do espetáculo teatral - catálogo da exposição. Curitiba: UTFPR, 2013b. Disponível em: < http:// repositorio.utfpr.edu.br/jspui/handle/1/3426 > . Acesso em: 01 mai. 2020.

SCHEFFLER, Ismael. A formação em cenografia e os cursos de Especialização em Cenografia da UTFPR. In: SCHEFFLER, Ismael; PORTO ALEGRE, Laíze Márcia. (Org.). Questões de cenografia I. Curitiba: Arte Final, 2014. p. 15-43. Disponível em: < https:// issuu.com/ismaelssss/docs/questoes_de_cenografia_i_vers_o_di >. Acesso em: 01 mai. 2020.

SCHEFFLER, Ismael. Espaço cenográfico: pensamentos sobre teatro e cenografia expandidos para a formação de designers. In: IX Congresso da Associação Brasileira de Pesquisa e Pós-Graduação em Artes Cênicas, 2016, Uberlândia / MG. Memória ABRACE XVI - Anais do IX Congresso da Associação Brasileira de Pesquisa e Pós-Graduação em Artes Cênicas. Uberlândia / MG: UFU, 2016a. p. 36543680. Disponível em: < https://www.publionline.iar. unicamp.br/index.php/abrace/article/view/1810 >. Acesso em: 01 mai. 2020.
SCHEFFLER, Ismael. La experimentación del espacio para la formación en escenografía. Escena Uno - Escenografía, dirección de arte y puesta en escena, v. 3, p. 1-18, 2016b. Disponível em: < http:// escenauno.org/la-experimentacion-del-espacio-para-la-formacion-en-escenografia/ > . Acesso em: 01 mai. 2020.

SCHEFFLER, Ismael. Considerações sobre quatro bases pedagógicas referenciais do Laboratório de Estudo do Movimento. Anais da V Jornada Nacional de Arquitetura, Teatro e Cultura - 04 a 06 de setembro de 2019, Rio de Janeiro, UNIRIO, 2019. Disponível em: < http://www.unirio.br/espacoteatral/arquivos/ evento-extensao/AnaisVjornadaNacionaldeArquiteturaTeatroeCultura. pdf?fbclid=IwAROSX _tj9mc3FEtRmzlwTxrGHfzvUIQpQEzGKbSjv-5SoOCDXys_7EF1Rs >. Acesso em: 01 mai. 2020.

SCHEFFLER, Ismael; LANDAL, Simone (Org.) Questões de cenografia II: cenografia no teatro e em outros contextos. Curitiba: Arte Final, 2016. Disponível em: < https://issuu.com/ismaelssss/docs/ livro_quest_es_de_cenografia_ii_ce $>$. Acesso em: 01 mai. 2020. 